\title{
Proceeding of the Third International Conference of the French-Speaking Society for Theoretical Biology
}

\author{
Slimane Ben Miled
}

Received: 19 February 2012/ Accepted: 28 February 2012/Published online: 6 March 2012

(C) Springer Science+Business Media B.V. 2012

The definition of theoretical biology may be controversial. Indeed, the basic definition of theoretical biology classifies it as biomathematics. It assumes that theoretical biology is divided into, at least, four subfields: Biological mathematical modeling, Relational biology/Complex systems biology, Bioinformatics and Biomodeling Computation. In epistemology, theoretical biology is defined as the action of "theorizing" life sciences. It aims to introduce laws; it highlights some biological phenomena and makes possible the identification of new biological principles. The latter definition does not imply a direct relationship with mathematics. In both cases, theoretical biology is a strongly multidisciplinary science, for the tools imported from other science and for the shared ideas.

This controversy was one of the main concerns of the French-speaking Society for Theoretical Biology (SFBT). In 1985, it succeeded the Association for the development of Theoretical Methods for Biology (AMTB). The initial purpose of AMTB was to organize Schools; rapidly it took a more general objective: "the development of methods and theoretical formalisms useful for fundamental biological research and its practical applications" 1 .

The origin of SFBT Conferences comes from 1975, when Jean-Henri Maresquelle $^{2}$, used to invite colleagues with different scientific backgrounds to round tables, twice a year. These meetings lead to scientifically fruitful multidisciplinary

\footnotetext{
1 Journal Official of France, November 15, 1981, p. 9999

2 Professor at the University of Strasbourg, born in 1898 and died in 1977.
}

\footnotetext{
S. B. Miled

ENIT-LAMSIN, Tunis el Manar University, 13, place Pasteur, Belvédère, B.P. 74, 1002 Tunis, Tunisia

S. B. Miled $(\bowtie)$

Tunis Pasteur Institute, Tunis el Manar University, Belvédère, 13, place Pasteur,

B.P. 74, 1002 Tunis, Tunisia

e-mail: slimane.benmiled@pasteur.rns.tn
} 
discussions on biology related scientific themes. These round tables were called the Maresquelle club for Theoretical Biology and remained active until 1984. Within this context, Pierre Delattre and Michel Thellier made in $1978^{3}$ the first Conference on models. Furthermore, two prices were created in order to encourage young scientists, the P. Delattre price in 1994 and the R. Thom price in 2007. The latter is given during the International Conference of the SFBT.

Thirty four years later, the Third International Conference of the SFBT held in Tunis from June 17-19, 2010, continue in this scope. The conference brought 70 participants from five different countries ${ }^{4}$. There were 33 oral presentations of 20 min and 6 plenary lectures of $40 \mathrm{~min}$. The R. Thom price was given to two young promising researchers, Chata Sanogo from University of Kenitra (Morocco) and Emna Hrigua from University of Tunis el Manar (Tunisia), underling the role of women in science and education and their significant contribution to the development of Universities especially in third world countries.

The present proceeding comes with twelve articles on theoretical biology, ranging from the molecular to the population scale and passing through gene, cellular and tissue scale. Articles were grouped into three different categories depending on the biological scales. These articles were proceeded by an article of L. Almeida et al., who discuss the interaction between different biological scales.

1. From molecule to cell: This part groups three articles: The articles of MinhUyen Dao Thi et al., Abdessalem Chekhchoukh et al. and Nicolas Glade.

2. From cell to individual: This part groups four articles: The articles of MarieClaire Verdus et al., Remis Costalat et al., Nadia Khalfa et al. and Linda El Alaoui et al.

3. From individual to ecosystem: This part groups five articles: The articles of Marco Marva et al., Mohamed Khaladi et al., Pierre Auger et al., Sanogo Chata et al. and Chakib Jerry et al.

Acknowledgments SBM and SFBT wish to thank the Tunisian Ministry of Higher Education and Scientific Research, TWAS, IRD and AUF for their financial support of the event. Readers interested in learning more about SFBT and its activities can consult its web site at http://www.sfbt.org.

\footnotetext{
${ }^{3}$ Conference proceedings in the series Interdisciplinary Researches, Maloine, 1979, p. 748.

4 Algeria, Canada, France, Mali, Mauritania, Mexico, Morocco, Spain, and Tunisia.
} 